\title{
Lung cancer in never smokers-the East Asian experience
}

\section{Fei Zhou, Caicun Zhou}

Department of Oncology, Shanghai Pulmonary Hospital, Tongji University School of Medicine, Shanghai 200433, China

Contributions: (I) Conception and design: All authors; (II) Administrative support: All authors; (III) Provision of study materials or patients: All authors; (IV) Collection and assembly of data: All authors; (V) Data analysis and interpretation: All authors; (VI) Manuscript writing: All authors; (VII) Final approval of manuscript: All authors.

Correspondence to: Prof. Caicun Zhou. Department of Oncology, Shanghai Pulmonary Hospital, Tongji University School of Medicine, No 507 Zhengmin Road, Yangpu District, Shanghai 200433, China. Email: caicunzhoudr@163.com.

\begin{abstract}
Approximately one third of all lung cancer patients in East Asia are never-smokers. Furthermore, the proportion of lung cancer in never smokers (LCINS) has been increasing over time. Never-smokers are more often diagnosed with adenocarcinoma in East Asia, a subtype largely defined by oncogenic drivers. In this subgroup of patients, as high as $90 \%$ of patients have been found to harbor well-known oncogenic mutations and can be successfully managed with targeted therapies inhibiting specific oncogenic mutant kinases. EGFR tyrosine kinase inhibitor (EGFR-TKI) treatment has been the most important targeted therapy in lung adenocarcinoma from East Asian never-smokers as approximately $70 \%$ of these patients have the opportunity to receive EGFR-TKI treatment. Lung squamous cell carcinoma (SQCC) and small cell lung cancer (SCLC) are two common histologic types of smoking-related non-small cell lung cancer (NSCLC). The proportion of never-smokers with SQCC and SCLC in East Asian patients seems to be higher than that in Caucasian patients. Recent studies also suggest that lung SQCC and SCLC in neversmokers may be distinct subtypes. Therefore, better understanding of the biologic characteristics of these subtypes of patients may provide new insights for the treatment. In this review, we will provide an overview of East Asian experience in the treatment of advanced, never-smoking lung cancer, focusing on etiologic factors in the development of LCINS, targeted therapy for never-smokers with adenocarcinoma, distinct characteristics of never-smokers with lung SQCC and SCLC, and the role of immunotherapy in neversmokers with NSCLC.
\end{abstract}

Keywords: Never-smokers; East Asian; targeted therapy; immunotherapy; lung cancer

Submitted Jan 01, 2018. Accepted for publication May 17, 2018.

doi: $10.21037 /$ tlcr.2018.05.14

View this article at: http://dx.doi.org/10.21037/tlcr.2018.05.14

\section{Introduction}

Lung cancer is the leading cause of cancer-related deaths in China and accounted for an estimated 610,000 deaths in 2015 (1). The majority of lung cancers are thought to be attributed to direct tobacco exposure. However, approximately $10 \%$ to $25 \%$ of all lung cancers occur in never smokers $(2,3)$, defined as those who smoked fewer than 100 cigarettes during their lifetime. Notably, epidemiologic studies reveal that the proportion of lung cancer in never smokers (LCINS) is higher in East Asia, including China, Japan, Mongolia, North Korea, and South
Korea, and approximately one third of all lung cancer patients are LCINS [39.7\% in China (our unpublished data), 38\% in South Korea (4) and 32.8\% in Japan (5)]. The high proportion of LCINS is mainly due to low smoking prevalence of East Asian females with lung cancer [9.9\% in South Korea, $17-25.6 \%$ in Japan, $28.3 \%$ in Hong Kong, $6.4 \%$ in Taiwan, and $5.2 \%$ in China (our unpublished data)], which was significantly lower than that in Caucasian female patients (ranging from 53\% to 91\%) (4-10). Meanwhile, the smoking rate of male patients with lung cancer is similar between East Asia and Western countries (Figure 1) 


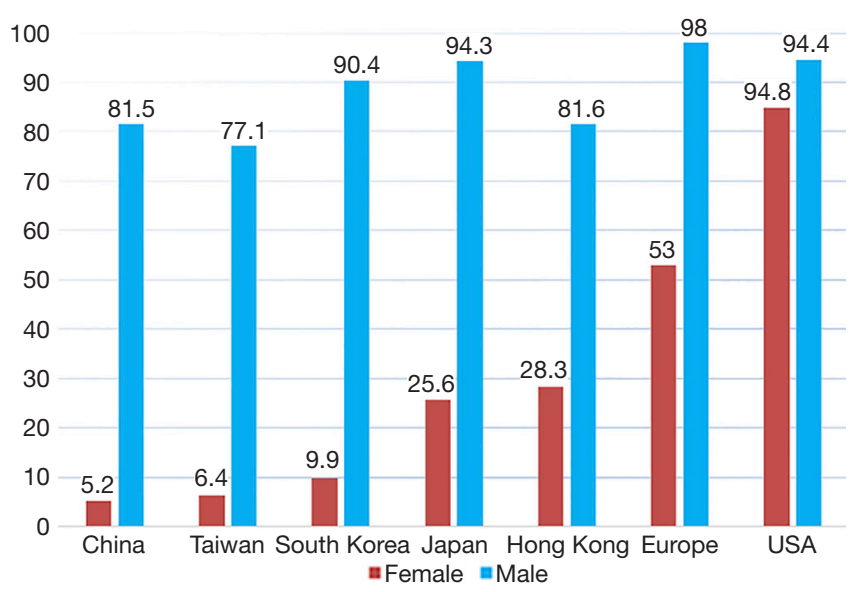

Figure 1 Smoking prevalence of lung cancer patients by gender in East Asia, Europe and USA.

(4-10). The proportion of LCINS has been increasing over time (5). Although the reason remains unknown, a better understanding of the epidemiologic and biologic characteristics of never-smokers has become increasingly important.

Never-smokers in East Asians are more often diagnosed with adenocarcinoma, a subtype largely defined by oncogenic drivers (11). The proportion of never-smokers in lung squamous cell carcinoma (SQCC) and small cell lung cancer (SCLC) is also higher among East Asian patients than in non-Asian patients $(12,13)$. Therefore, oncologists in East Asia have more opportunities to treat never-smoking patients with non-small cell lung cancer (NSCLC) in clinical practice. In this review, we will provide an overview of the East Asian experience in the treatment of advanced, never-smoking lung cancer.

\section{Etiologic factors in the development of LCINS}

Given the dominant role of tobacco exposure in the development of lung cancer, risk factors that contribute the pathogenesis of lung cancer have also been comprehensively investigated. The role of environmental tobacco exposure in the development of LCINS has been widely studied. A recent pooled study from 18 case-control studies in the International Lung Cancer Consortium, including 766 cases and 1,954 control who were never-smokers from Asian, has demonstrated that exposure to second-hand smoke is associated with an increased risk of lung cancer in neversmokers [odds ratio $(\mathrm{OR})=1.31,95 \%$ confidence interval (CI), 1.17-1.47) (14). Moreover, the strongest association was observed in SCLC (OR $=1.26,95 \%$ CI: $1.10-1.44$ for adenocarcinoma; OR $=1.41,95 \%$ CI: $0.99-1.99$ for SQCC; $\mathrm{OR}=1.48,95 \%$ CI: $0.89-2.45$ for large cell lung cancer; OR $=3.09$, 95\% CI: $1.62-5.89$ for SCLC) (14). Based on data from the Global Adult Tobacco Survey (GATS) conducted from December 2009 to March $2010(15,16)$, the prevalence of current smokers in adult age more than 15 years old was $28.1 \%$ in China, with an estimated more than 300 million current smokers. Due to lack of effective strategies for tobacco control for the public, exposure to secondhand smoke both at home and the workplace may play an important role in the development of LCINS in China.

Another important factor associated with an increased risk of LCINS is exposure to cooking fumes, as several case-control studies have identified cooking oil fumes as a risk factor for lung cancer among Chinese never-smoking women (17-20). A recent meta-analysis including 13 studies, with a total of 3,596 lung cancer women and 6,082 healthy controls also validated the positive relationship between cooking oil fume exposure and lung cancer among Chinese never-smoking women, with a risk ratio (RR) of 1.74 (95\% CI: 1.57-1.94) (21).

Other factors that play a role in the etiology of LCINS in non-smokers from East Asia also include inherited genetic susceptibility (22-24), occupational and environmental exposure (25), hormonal factors (26), pre-existing lung diseases (27-30), suggesting that the etiopathogenesis of LCINS is a complex process with multiple risk factors involved.

\section{Lung adenocarcinoma in never-smoking East Asian: a subtype largely defined by oncogenic drivers}

Considerable molecular epidemiologic studies have demonstrated that lung adenocarcinoma from East Asian never-smokers is a distinct subtype that can be largely defined by targetable oncogenic drivers (11,31-35) (Figures 2,3). In this subgroup of patients, as high as $90 \%$ of patients have been found to harbor well-known oncogenic mutations and LCINS seems to be substantially driven by a single gene $(11,32)$. On the other side, smoking-related lung cancer is a more distinct entity, with higher mutation burden, somatic single-nucleotide variations (SNVs) and higher frequency of $\mathrm{C}: \mathrm{G} \rightarrow \mathrm{A}: \mathrm{T}$ transversions (39). Smoking status may also have an impact on EGFR mutations, the frequency of EGFR mutations ranged from $22.0 \%$ to $43.5 \%$ in Chinese smokers with adenocarcinoma $(40,41)$. Therefore, targeted therapy 


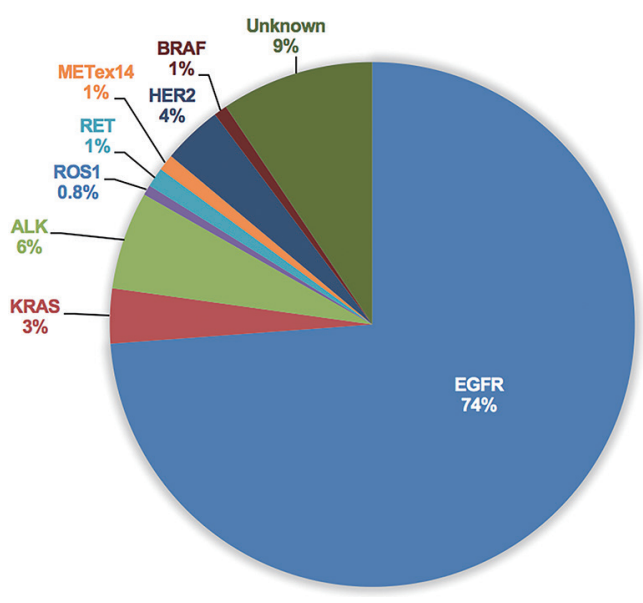

Figures 2 Pooled analysis of frequency of driver genes in adenocarcinoma from 8 studies, including 2,126 East Asian Never Smokers (11,31-33,35-38).

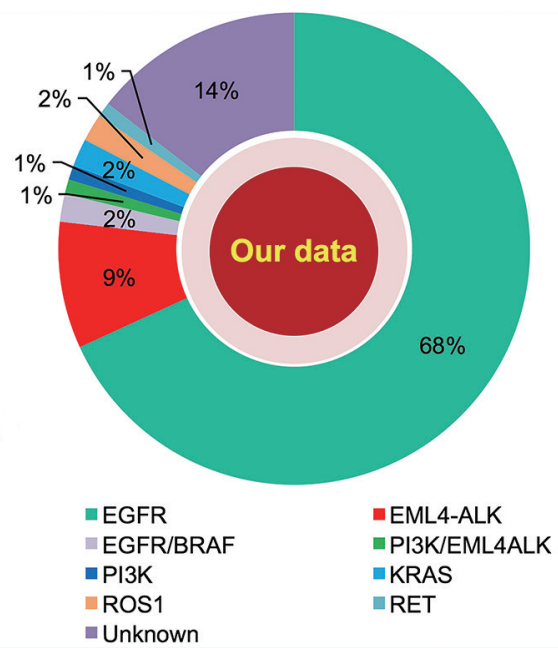

Figure 3 Distribution of common driver genes in never-smokers with adenocarcinoma in cases from Shanghai Pulmonary Hospital, from 2012 to 2016.

inhibiting oncogenic mutant kinases plays a pivotal role for the treatment of lung adenocarcinoma in never-smoking East Asians.

\section{EGFR sensitizing mutations}

EGFR sensitizing mutation is the most common driver gene found in never-smoker adenocarcinoma from East Asia, constituting $60-78 \%$ of this subgroup (11,32,35-37). Robust evidence has identified EGFR sensitizing mutation as the most relevant predictor of response to the EGFR tyrosine kinase inhibitors (EGFR-TKIs) (42-44). Several randomized phase III trials have consistently demonstrated that gefitinib, erlotinib and afatinib are more effective in terms of objective response rate (ORR) and progression-free survival (PFS), and better tolerated than standard platinumbased doublet chemotherapy in advanced NSCLC patients harboring EGFR activating mutation. Among these trials, IPASS, LUX-LUNG 6 trial was conducted in Asian $(45,46)$, First-SIGNAL trial was conducted in South Korea (47), OPTIMAL, ENSURE, and CONVINCE trial were conducted in China (48-50), WJTOG3405 and NEJ002 trial were conducted in Japan $(51,52)$. To date, EGFR-TKI treatment has been the most important targeted therapy in lung adenocarcinoma from East Asia never-smokers as approximately $70 \%$ of these patients have the opportunity to receive EGFR-TKI treatment. Of note, although the above-mentioned trials did not enroll EGFR-mutant patients based on histologic type and smoking status, most of the enrolled patients (ranging from $87 \%$ to $100 \%$ ) presented with adenocarcinoma histology. Furthermore, of the 1,416 patients enrolled in the six trials that only included EGFR-mutant patients (LUX-LUNG 6, OPTIMAL, ENSURE, CONVINCE, WJTOG3405 and NEJ002 trial), only $27.9 \%(395 / 1,416)$ were former or current smokers. A recent meta-analysis revealed that smoking status may have an adverse impact on the PFS benefit of EGFR-TKI treatment (pooled HR for PFS of never-smokers, 0.32, 95\% CI: 0.27-0.37, treatment-smoking interaction $\mathrm{P}=0.02$ ). However, current or former smokers can also derive PFS benefit from EGFR-TKI treatment (pooled HR for PFS, 0.50, 95\% CI: 0.40-0.63) (53).

Although initial response is often tremendous, most patients, if not all, eventually become resistance to EGFRTKIs. Prospective trials have investigated the role of continuation of EGFR-TKIs beyond progression (54-57). ASPIRATION trial was a phase 2, open-label, single-arm study conducted in Hong Kong, South Korea, Taiwan, and Thailand, including patients with stage IV, EGFRmutant NSCLC (54). Of the 207 enrolled patients, $72.9 \%$ (151/207) were never-smokers and 97.1\% (201/207) presented with adenocarcinoma histology. ASPIRATION trial demonstrated that continuing erlotinib therapy beyond progression result in a 3.1-month improvement in PFS, suggesting continuing erlotinib therapy beyond progression is feasible in Asian patients. IMPRESS trial was a phase 3 randomized trial that compared the continuation of gefitinib plus chemotherapy with placebo plus chemotherapy 
in patients with $E G F R$ mutation-positive advanced NSCLC after failure of first-line gefitinib (56). However, continuation of gefitinib in combination with platinumbased chemotherapy did not prolong PFS as compared with chemotherapy alone (median PFS: 5.4 vs. 5.4 months, HR $=0.86,95 \%$ CI: $0.65-1.13, \mathrm{P}=0.27$ ) (56). Recent updated OS and biomarker analyses demonstrated that continuation of gefitinib plus chemotherapy had a detrimental effect on OS when compared with chemotherapy alone (median OS, 13.4 vs. 19.5 months, HR =1.44, 95\% CI: 1.07-1.94; $\mathrm{P}=0.016$ ) (57). Furthermore, the detriment effect was significantly shown in patients with T790M mutationpositive plasma samples (HR $=1.49,95 \%$ CI: $1.02-2.21$, $\mathrm{P}=0.0432$ ) (57). IMPRESS trial suggested that platinumbased doublet chemotherapy remains the standard of care when acquired resistance develops and the detrimental effect of continuation of gefitinib may be driven by T790Mpositive status. Our recent retrospective study also showed that patients may derive modest benefit from continuation of gefitinib in T790M mutation-negative tumors (58).

The emergence of T790M secondary mutations at exon 20 remains the dominant cause of acquired resistance to EGFR-TKIs. T790M mutations occur in about half of acquired resistant cases in East Asian patients (59-61). Furthermore, T790M mutations is also the major acquired resistance mechanism of afatinib in East Asian patients, presenting in $47.6 \%(20 / 42)$ acquired resistant cases (62). Osimertinib (AZD9291) is an oral, potent, irreversible EGFR-TKI selective for both EGFR sensitizing mutations and T790M resistance mutations. Serial trials have investigated the efficacy of osimertinib in patients with T790M resistance mutations, with an ORR of $61 \%$ to $70 \%$ and median PFS of 9.6 to 12.3 months (63-65). AURA3 trial was a randomized, international, open-label, phase 3 trial that compared osimertinib with platinum-based therapy plus pemetrexed in T790M-positive patients (66). Osimertinib resulted in a significant improvement in ORR (71\% vs. $31 \%, \mathrm{P}<0.001)$ and PFS (10.1 vs. 4.4 months; HR $=0.30,95 \%$ CI: $0.23-0.41, \mathrm{P}<0.001)$ when compared with standard chemotherapy. AURA17 was an open-label, singlearm, phase II study that evaluated the safety and efficacy of osimertinib in East Asian T790M-positive patients (67). Of the enrolled 171 patients, the ORR was $63 \%$ and median PFS was 9.7 months, which was consistent with the results observed from global data. To date, osimertinib has been approved for patients with T790M resistance mutations after failure of first- or second-generation EGFR-TKIs in China, Japan and South Korea.

\section{ALK/ROS1/RET rearrangement}

Chromosomal rearrangement involving receptor tyrosine kinase (RTK) in lung cancer was first discovered in 2007 and currently rearrangements in three major RTKs have been identified as therapeutic targets in NSCLC.

\section{ALK}

$A L K$ rearrangement defines another distinct subtype of patients with NSCLC, accounting for about $5 \%$ of all NSCLC cases (68). In never-smoker adenocarcinoma from East Asian, the frequency of $A L K$ rearrangement range from $4.95 \%$ to $9.6 \%(11,31-35,69)$, which was similar with that in Caucasian. Crizotinib is an oral small-molecule TKI of $A L K, M E T$, and ROS1 kinases and has been approved for the first-line treatment of advanced $A L K$-rearranged NSCLC based on the results from PROFILE1014 trial (70). Nishio et al. recently reported a post-hoc analysis of the safety and efficacy of crizotinib in Asian populations from two global phase III trials (PROFILE1007 and PROFILE1014) (71). Consistent with the observations of overall patient populations, crizotinib also demonstrated better PFS (previously treated: 7.7 vs. 3.0 months, HR $=0.49,95 \%$ CI: $0.37-0.64, \mathrm{P}<0.001$; previously untreated: 13.6 vs. 7.0 months, HR $=0.44,95 \%$ CI: $0.30-0.65$, $\mathrm{P}<0.001$ ) and ORR (previously treated:75\% vs. $22 \%$, $\mathrm{P}<0.05$; previously untreated: $70 \%$ vs. $54 \%, \mathrm{P}<0.05)$ vs. chemotherapy both in previously treated and untreated Asian patients with $A L K$-positive NSCLC. The safety profile and efficacy were similar between Asian patients and non-Asian patients. PROFILE1029 trial was a randomized, phase 3 trial that compared crizotinib with platinum-based therapy plus pemetrexed in Chinese and Asian patients with $A L K$-positive tumors (72). The median PFS (11.1 months) and ORR (88\%) were consistent with that observed in the PROFILE 1014 trial. To date, crizotinib has been proved as standard first-line therapy for patients with $A L K$-positive NSCLC in China, Japan and South Korea. Alectinib is a highly selective $A L K$ inhibitor with high brain-penetrant that has shown high anti-tumor activity both in $A L K$ inhibitor-naïve and crizotinib-resistant patients (73-75). J-ALEX trial was a randomized, open-label, phase 3 trial comparing alectinib with crizotinib in Japanese patients with previously crizotinib-naive, advanced $A L K$-positive NSCLC (76). J-ALEX trial showed the superiority of alectinib over crizotinib in terms of PFS (not reached vs. 10.2 months, $\mathrm{HR}=0.34,99.7 \% \mathrm{CI}: 0.17-0.71, \mathrm{P}<0.001)$. Dose interruptions due to adverse events were also significantly 
reduced with use of alectinib as compared with crizotinib (29\% vs. $74 \%$ ). The results of J-ALEX trial were further confirmed in ALEX trial and suggested the superiority of alectinib over crizotinib both in Asian and non-Asian $A L K$ positive NSCLC (77).

\section{ROS1}

ROS1 is another RTK that shares extensive amino acid sequence homology with $A L K$. Clinical characteristics of patients with ROS1 rearrangement are similar to those observed in patients with $A L K$-rearranged NSCLC $(78,79)$. Although ROS1 rearrangement was predominantly identified in never-smokers with adenocarcinoma, the alteration has also been found in patient with SQCC (80), adenosquamous $(81,82)$, adenocarcinoma/SCLC (83), and even large cell carcinoma (84). Generally, the frequency rate of ROS1 rearrangement was very low, with a prevalence ranging from $1 \%$ to $2 \%$ in Asian patients. Results from a phase I study (PROFILE1001) demonstrated that crizotinib was highly active in patients with ROS1-rearranged NSCLC; $72 \%(36 / 50)$ of enrolled patients responded to crizotinib and the PFS was amazing 19.2 months (85). Recently, second-generation $A L K / R O S 1$ inhibitor (ceritinib) (86), third-generation $A L K / R O S 1$ inhibitor (lorlatinib) (87) and multitarget TKIs (entrectinib and cabozantinib) $(88,89)$ also demonstrated potent activity in patients with ROS1rearranged NSCLC. In a large East Asian phase II study of crizotinib, the ORR was $69 \%$ and median PFS was 13.4 months in 127 patients with ROS1-rearranged NSCLC (90). In a South Korean phase II study, 32 patients with ROS1-rearranged NSCLC were treated with ceritinib (86). The ORR was $62 \%$ and median PFS was 9.3 months for all patients and 19.3 months for crizotinib-naïve patients.

Approximately 1\% of lung adenocarcinoma are driven by oncogenic RET rearrangements (91). RET-rearranged tumors are commonly found in young never-smokers with a solid-predominant subtype of adenocarcinoma, constituting $1.4 \%$ of NSCLC and $1.7 \%$ of adenocarcinoma in Chinese patients (91). Consistently, the identified RETrearranged patients in our previous study were all neversmokers (92). Independent investigators have evaluated the role of multikinase RET inhibitors, such as cabozantinib and vandetanib, in RET-rearranged NSCLC (93-95). Yoh et al. recently reported the activity of vandetanib in 19 patients with RET-rearranged Japanese NSCLC in a phase II trial (94). The ORR, median PFS, and median OS in overall patients were $47 \%, 4.7$ months, and 11.1 months. Of note, the CCDC6-RET subtype showed a higher sensitivity to vandetanib than did the KIF5B-RET subtype [ORR: $20 \%$ (2/10) vs. 83\% (5/6); median PFS: 2.9 vs. 8.3 months; median OS: 11.1 months vs. not reached] (94). GLORY (the Global, Multicenter RET Registry) was the largest single database of patients with $R E T$-rearranged lung cancers (96). When the data was carried out, 165 patients with $R E T$-rearranged NSCLC from 29 centers across Europe, Asia, and the USA were accrued. Of those, 53 patients were treated with a RET inhibitor. The ORR, median PFS, and median OS were $26 \%$, 2.3 months and 6.8 months, respectively. Regarding specific RET inhibitors, the ORR of cabozantinib, vandetanib, and sunitinib was $37 \%, 18 \%$, and $22 \%$, median PFS was 3.6 , 2.9, and 2.2 months and median OS was 4.9, 10.2 and 6.8 months, respectively. Notably, the ORR and PFS or OS were not statistically significant different by various fusion subtypes (KIF5B vs. other partner) (96).

In summary, the epidemiologic and clinical characteristics of East Asian patients with $A L K / R O S 1 / R E T$ rearrangements were similar with those of Caucasian patients. Although clinically meaningful benefit was seen with RET inhibition therapy in both Asian and non-Asian patients, its activity was lower than those treated with $A L K$ or ROS1 inhibitors in patient with $A L K$ or $R O S 1$ rearrangements. Multikinase inhibitors might not be the most effective strategy for this subtype of patients and highly RET-specific TKIs are needed.

\section{MET 14 exon (METex14) skipping}

METex14 skipping has been recently identified as a rare oncogenic alteration in NSCLC (97), with an overall frequency of $2.7-3.0 \%$ in Caucasian patients $(97,98)$. Among 795 East Asian NSCLC patients, the prevalence of METex14 skipping was 2.1\% (17/795) (99). Of 45 patients with quintuple-negative lung adenocarcinoma (EGFR/ KRAS/ALK/ROS1/RET negative), 37.8\% (17/45) of patients had METex14 skipping. The incidence of never-smokers in patients with METex14 skipping (41.2\%) was significantly lower than that in patients with EGFR mutations or ROS1 rearrangements (99). In another study including 1,296 Chinese patients with NSCLC, METex14 skipping occurred in $1 \%(12 / 1,296)$ of all NSCLC cases $(100)$. Of these cases, 10 were with adenocarcinoma histology, 1 with adenosquamous, and 1 with SQCC. Among METex14 skipping adenocarcinoma, $50 \%$ were never-smokers. The prevalence of METex14 skipping in East Asian patients (1\% to $2.1 \%$ ) seemed to a bit lower than that in Caucasian patients $(38,98,100)$. Preclinical data and case reports 
suggested that patients with METex14 skipping can derive clinical benefit from MET inhibitors (crizotinib and INC280) $(97,101)$. However, in two cases of Chinese patients with METex14 skipping treated with crizotinib, 1 patients responded to crizotinib with a PFS of 9 months and the other one experienced disease progression only 1 month later, mainly due to co-existing with Kras mutations (100).

\section{HER2 mutations}

HER2 is a member of the EGFR family of RTKs, which also includes EGFR (HER1), HER3 and HER4. In the Chinese population, the prevalence of HER2 mutations ranged from $2.4 \%$ to $5.94 \%$, a little more common than Caucasian population $(11,32,35,69,102-104)$. In our previous study, HER-2 mutation was detected in $4.8 \%$ (22/456) of EGFR wild-type lung adenocarcinoma (105). Recently, HER 2 inhibition therapy with small molecular TKIs, such as afatinib, dacomitinib, neratinib, and lapatinib, may represent a promising therapeutic option in patients with HER2 mutations (106-110). Pyrotinib (SHR1258, discovered by Shanghai Hengrui Pharmaceutical CO., Ltd.) was a novel irreversible EGFR/HER2 dual TKI and demonstrated robust anti-tumor activity in HER2-positive breast cancer both in vivo and in vitro (111). In a phase I study of pyrotinib in HER2-positive metastatic breast cancer, the maximum tolerated dose was established as 400 $\mathrm{mg}$ (112). Of 36 evaluable patients, the ORR was $50 \%$ and median PFS was 35.4 weeks. Furthermore, the ORR was impressive and 10 out of $12(83.3 \%)$ patients achieved an objective response in trastuzumab-pretreated patients. Ren et al. recently reported preliminary results of a phase II study about the efficacy and safety of pyrotinib in Chinese patients with HER2-mutant advanced NSCLC (113). By Jul 21, 2016, 11 patients were treated with pyrotinib at a dose of 320 or $400 \mathrm{mg}$ orally per day. The ORR was $54.5 \%$ $(6 / 11)$ and disease control rate (DCR) was $81.1 \%(8 / 11)$. The median PFS was 6.2 months and side effects were mild. This trial is still ongoing (NCT02535507) and we expectantly await further results.

\section{Lung SQCC or SCLC in never-smoking East Asian: potentially distinct subtypes?}

Lung SQCC and SCLC are two common histologic type of smoking-related lung cancer. The incidence of neversmoking lung cancer increased over time both in Asian patients and non-Asian patients, although the reason remains unknown. Furthermore, the proportion of neversmokers is higher among Asian patients with lung cancer than in non-Asian patients, therefore, a better understanding of the epidemiologic and biologic characteristics of neversmokers has become increasingly important, especially in Asian patients.

Huang et al. recently characterized the clinical features and specific driver genes status of never-smoking lung SQCC in 597 Chinese patients (114). Overall, 14.7\% (88/597) were never-smokers. The never-smokers were more likely to be female patients than ever-smokers $(42.05 \%$ vs. $1.57 \%, \mathrm{P}<0.001)$. Among the 76 never-smokers who had high quality tissue to detect oncogenic mutations, 16 harbored known oncogenic mutations, including 10 (13.16\%) EGFR mutations, 1 (1.32\%) Kras mutations, 2 (2.63\%) HER2 mutations, 1 (1.32\%) BRAF mutations, 2 (2.63\%) PIK3CA mutations and 2 (2.63\%) FGFR fusion. The prevalence of oncogenic drivers was significantly higher in never-smokers than that in ever-smokers (21.05\% vs. $11.05 \%, \mathrm{P}=0.023)$, especially $E G F R$ mutations (13.16\% vs. $3.40 \%, \mathrm{P}=0.001)$. Furthermore, never-smokers tended to have poorer OS than ever-smokers. In another study of South Korean patients, 5.0\% (19/379) were never-smokers (115). Similarly, of these 19 patients, 52.5\% $(10 / 19)$ were females. The investigators further analyzed fifty cancer-related genes in never-smokers (12 patients) and ever-smokers (14 patients). Although the distribution of hotspot mutations in never-smokers was similar to that in ever-smokers, EGFR mutations were found in both neversmokers and ever-smokers. Generally, in SQCC patients with EGFR sensitizing mutations, EGFR-TKIs are generally less effective than in adenocarcinoma (116). Of note, in that study, among 4 never-smokers with lung SQCC with evaluable data, 1 achieved complete response, 1 achieved partial response, and 2 achieved stable disease (116). In another study conducted in China, among 51 nonadenocarcinoma patients with EGFR sensitizing mutations treated with EGFR-TKIs (26 with SQCC), the median PFS was longer in never-smokers than ever-smokers (5.49 vs. 3.78 months, $\mathrm{P}=0.036$ ) (117). Several cases also observed a significantly clinical benefit from crizotinib or alectinib in patients with $A L K / R O S 1$-rearranged SQCC (118-122) (Table 1). Interestingly, all these patients mentioned above were never-smokers and one patient who did not respond to alectinib was an ever-smoker SQCC (123) (Table 1). These results, at least in part, suggest that lung SQCCs in neversmokers may be a distinct subtype, and further research into lung SQCC in never-smokers is needed. 
Table 1 Cases of East Asian patients with squamous cell carcinoma harboring $A L K / R O S 1$ fusions

\begin{tabular}{|c|c|c|c|c|c|c|c|c|c|c|c|c|}
\hline Author & Year & Race & Gender & $\begin{array}{c}\text { Age } \\
\text { (years) }\end{array}$ & Pathology & $\begin{array}{c}\text { Smoking } \\
\text { status }\end{array}$ & Stage & $\begin{array}{l}\text { Molecular } \\
\text { alteration }\end{array}$ & treatment & Best response & $\begin{array}{c}\text { PFS } \\
\text { (months) }\end{array}$ & Reference \\
\hline Wang et al. & 2014 & Chinese & Female & 55 & SQCC & Never & IV & ALK fusion & Crizotinib & Partial response & $5.8+$ & $(118)$ \\
\hline Zhang et al. & 2015 & Chinese & Female & 55 & SQCC & Never & IV & ALK fusion & Crizotinib & Partial response & 6 & (119) \\
\hline Wang et al. & 2016 & Chinese & Female & 37 & SQCC & Never & IIIB & ALK fusion & Crizotinib & Partial response & $9+$ & (120) \\
\hline Li et al. & 2017 & Chinese & Female & 47 & SQCC & Never & IV & $\begin{array}{l}\text { ALK-ROS1 } \\
\text { fusion }\end{array}$ & Crizotinib & Partial response & 5 & $(122)$ \\
\hline Tamiya et al & 2015 & Japanese & Male & 78 & SQCC & Ever & Unknown & ALK fusion & Alectinib & Stable disease & $1.5+$ & (123) \\
\hline
\end{tabular}

PFS, progression-free survival; SQCC, squamous cell carcinoma.

The prevalence of never-smokers with SCLC in Caucasian patients is very low, accounting for $2.0 \%$ to $2.5 \%$ of all SCLC cases $(124,125)$. Two recent studies showed that the proportion of never-smokers with SCLC in East Asian patients was higher than that in Caucasian patients $(12,13)$. In the study by Sun et al., 13\% (50/391) were never-smokers in South Korean patients. In our study, 22.8\% (69/303) were never-smokers in Chinese patients (12). Furthermore, more than $80 \%$ of never-smokers were females. Both studies demonstrated that never-smokers with SCLC had better survival than ever-smokers $(12,13)$. Of 28 genetically evaluable never-smokers, EGFR mutations were detected in four cases $(14.3 \%)$, and other molecular alterations included TP53 in 26 cases (92.9\%), RB1 in 7 cases (25\%), PTEN in 5 cases $(17.9 \%)$, MET in 4 cases $(14.3 \%)$, and SMAD4 in 3 cases $(10 / 7 \%)$ in the study by Sun et al. (13). Although EGFR mutations can be found in SCLC phenotypically transformed from adenocarcinoma as an acquired resistance mechanism to EGFR-TKIs, these 4 cases were found in patients with de novo SCLC. A recent case revealed that one never-smoking patient with de novo SCLC harboring EGFR exon 19 deletion but had no response to erlotinib (126). However, due to the high proportion of never-smokers among Asian SCLC patients, better understanding of the biologic characteristics of these subtypes of patients may provide new insights for the treatment strategies that have not changed for decades.

\section{Immunotherapy in never-smoking East Asian: can a patient population not always be blessed?}

Immunotherapy with immune checkpoint blockade targeting the programmed-death 1/programmed-death ligand 1 (PD-1/PD-L1) axis represents a novel approach for the treatment of patients with advanced NSCLC (127). Several randomized trials have demonstrated a significant survival advantages of $\mathrm{PD}-1 / \mathrm{PD}-\mathrm{L} 1$ antibodies over docetaxel as second-line therapy (128-132). Furthermore, pembrolizumab has been approved as first-line therapy for advanced NSCLC patients with PD-L1 positive tumors $(\geq 50 \%)$ based on the results of KEYNOTE-024 trial (133). Of note, the current obstacle to the wide use of anti-PD-1/ PD-L1 antibodies is lack of biomarker to identify beneficial patient population because only about $20 \%$ of patients with NSCLC respond to anti-PD-1/PD-L1 antibodies. Tumor mutation burden (TMB) has recently been identified as a promising biomarker for response to immune checkpoint inhibitors (134). Patients with high nonsynonymous burden had higher ORR ( $63 \%$ vs. $0 \%, \mathrm{P}=0.03)$ and better PFS (14.5 vs. 3.7 months, $\mathrm{HR}=0.19,95 \%$ CI: $0.05-0.70, \mathrm{P}=0.01$ ) than those with low nonsynonymous burden. High TMB can increase the number of neoantigens, which are recognized by $\mathrm{T}$ cells, therefore enhancing tumor immunogenicity and leading to an antitumor immune response (134). These preliminary findings have been confirmed in an exploratory analysis of CheckMate-026 trial (135). In CheckMate-026 trial, although nivolumab did not prolong the PFS as compared with chemotherapy in patients with previously untreated advanced NSCLC with PD-L1-positive tumors $(\geq 5 \%)$, the ORR (47\% vs. $28 \%$ ) and PFS (9.7 vs. 5.8 months, HR $=0.62$, 95\% CI: $0.38-1.00$ ) were significantly improved with the use of nivolumab in patients with high TMB (135). Genomic analysis has demonstrated that smokers had a significantly higher number of mutations 
per Mb (median 10.5, range 4.9-17.6) than neversmokers with NSCLC (median 0.6, range 0.6-0.9) (134). Therefore, smokers are more likely to induce greater TMB and derive clinical benefit from checkpoint inhibitors than never-smokers. Interestingly, Kinoshita et al. found that non-smokers with adenocarcinoma can generate an immunosuppressive tumor microenvironment and inhibit $\mathrm{CD}^{+}$T-cell activation, suggesting checkpoint inhibitors may not be effective in this subtype of patients (136). However, in a recent meta-analysis, the treatment benefit for checkpoint inhibitors was independent of smoking history (current and former smokers vs. never smokers: HR for death, 0.69 vs. 0.79; interaction, $\mathrm{P}=0.40$ ) (137). Actually, it is the molecular smoking signature rather than selfreported smoking history that is significantly related to the clinical benefit from checkpoint inhibitors (134). Therefore, there is currently lack of robust evidence to select the beneficial population by smoking history for checkpoint inhibitor therapy.

As mentioned above, the vast majority of neversmoking East Asians with NSCLC have adenocarcinoma, a subtype largely defined by oncogenic drivers. Although tremendous efficacy has been achieved in these patients with the administration of targeted therapy, the survival outcomes are not satisfactory. Whether checkpoint inhibitors can generate a durable response of these patients, therefore, becomes of great importance. However, recent randomized trials and meta-analysis revealed that patients with EGFR mutations did not derive survival benefit from checkpoint inhibitors (128-132,138). A recent retrospective study also demonstrated that $E G F R$ mutations or $A L K$ rearrangement was associated with low response to checkpoint inhibitors $(3.6 \%, 1 / 28)$ (139). The poor response to checkpoint inhibitors in patients with EGFR mutations or $A L K$ rearrangement may result from a potentially immunosuppressive microenvironment in these patients (139). EGFR mutation was also correlated with uninflamed phenotype and weak immunogenicity, with decreased PD-L1 expression, lack of T-cell infiltration, and lower TMB (140). A recent report showed that High CD73 expression in EGFR-mutant NSCLC may be another cause that contribute to the reduced benefit from checkpoint inhibitors, which can alter immune cell function and is correlated with low PD-L1 expression (141). Sabari et al recently reported preliminary results of immunotherapy in NSCLC with METex14 skipping (142). However, only 1 patient $(6.7 \%, 1 / 15)$ responded to checkpoint inhibitors and median PFS was only 2.3 months. TMB was lower in patients with METex14 skipping and no partial response was observed even in patients with high TMB (142). Current evidence suggests that never-smoking adenocarcinoma from East Asia, the potentially beneficial population of targeted therapy, do not seem to be the same beneficial population of immunotherapy.

Notably, although this review focuses on East Asia, most of the data comes from China, Japan, and South Korea and we have little information about Mongolia and North Korea. Furthermore, China is a huge country with a diverse ethnic population. Almost all the reported data in Chinese targets Han population. As the ethnic minorities have distinct life-styles, growing backgrounds, diets and living conditions compared with Han population, the genetic profiles may also differ. For example, Uyghur population, mainly living in North-west of China, had significantly lower EGFR mutation rate than Han population (12\% vs. $55.1 \%$ ) (143). Therefore, these experiences and treatment strategies cannot be directly generalized to other East Asians, namely Mongolians and North Koreans, and Chinese ethnic minorities, and further studies are still needed in these populations.

\section{Conclusions}

In summary, approximately one third of all lung cancer patients in East Asia are LCINS. Never-smokers are more often diagnosed with adenocarcinoma in East Asian, a subtype largely defined by oncogenic drivers. In this subgroup of patients, as high as $90 \%$ of patients have been found to harbor well-known oncogenic mutations and can be successfully managed with targeted therapy inhibiting specific oncogenic mutant kinases. Lung SQCC and SCLC are two common histologic type of smokingrelated NSCLC. The incidence of LCINS also increases over time in East Asian patients. Recent studies suggest that lung SQCC and SCLC in never-smokers may be distinct subtypes, and better understanding of the biologic characteristics of these subtypes of patients may provide new insights for the treatment of these patients. Although Immunotherapy with immune checkpoint blockade generates durable response in some patients with advanced NSCLC, lung adenocarcinoma from East Asian neversmokers do not seem to be the beneficial population. These findings may reflect the considerably lower total mutation burden (and thus fewer neoantigens) in never smokers. However, there is currently lack of robust evidence to guide checkpoint inhibitor treatment by smoking history. 


\section{Acknowledgements}

None.

\section{Footnote}

Conflicts of Interest: The authors have no conflicts of interest to declare.

\section{References}

1. Chen W, Zheng R, Baade PD, et al. Cancer statistics in China, 2015. CA Cancer J Clin 2016;66:115-32.

2. Ferlay J, Shin $\mathrm{HR}=$ Bray F, et al. Estimates of worldwide burden of cancer in 2008: GLOBOCAN 2008. Int J Cancer 2010;127:2893-917.

3. Parkin DM, Bray F, Ferlay J, et al. Global cancer statistics, 2002. CA Cancer J Clin 2005;55:74-108.

4. Cho J, Choi SM, Lee J, et al. Proportion and clinical features of never-smokers with non-small cell lung cancer. Chin J Cancer 2017;36:20.

5. Yano T, Miura N, Takenaka T, et al. Never-smoking nonsmall cell lung cancer as a separate entity: clinicopathologic features and survival. Cancer 2008;113:1012-8.

6. Kosaka T, Yatabe Y, Endoh H, et al. Mutations of the epidermal growth factor receptor gene in lung cancer: biological and clinical implications. Cancer Res 2004;64:8919-23.

7. Tam IY, Chung LP, Suen WS, et al. Distinct epidermal growth factor receptor and KRAS mutation patterns in non-small cell lung cancer patients with different tobacco exposure and clinicopathologic features. Clin Cancer Res 2006;12:1647-53.

8. Hsu LH, Chu NM, Liu CC, et al. Sex-associated differences in non-small cell lung cancer in the new era: is gender an independent prognostic factor? Lung Cancer 2009;66:262-7.

9. Mitsudomi T. Molecular epidemiology of lung cancer and geographic variations with special reference to EGFR mutations. Transl Lung Cancer Res 2014;3:205-11.

10. Kobrinsky NL, Klug MG, Hokanson PJ, et al. Impact of smoking on cancer stage at diagnosis. J Clin Oncol 2003;21:907-13.

11. Sun Y, Ren Y, Fang Z, et al. Lung adenocarcinoma from East Asian never-smokers is a disease largely defined by targetable oncogenic mutant kinases. J Clin Oncol 2010;28:4616-20.
12. Liu X, Jiang T, Li W, et al. Characterization of neversmoking and its association with clinical outcomes in Chinese patients with small-cell lung cancer. Lung Cancer 2018;115:109-15.

13. Sun JM, Choi YL, Ji JH, et al. Small-cell lung cancer detection in never-smokers: clinical characteristics and multigene mutation profiling using targeted nextgeneration sequencing. Ann Oncol 2015;26:161-6.

14. Kim CH, Lee YC, Hung RJ, et al. Exposure to secondhand tobacco smoke and lung cancer by histological type: a pooled analysis of the International Lung Cancer Consortium (ILCCO). Int J Cancer 2014;135:1918-30.

15. Li Q, Hsia J, Yang G. Prevalence of smoking in China in 2010. N Engl J Med 2011;364:2469-70.

16. Giovino GA, Mirza SA, Samet JM, et al. Tobacco use in 3 billion individuals from 16 countries: an analysis of nationally representative cross-sectional household surveys. Lancet 2012;380:668-79.

17. Yu IT, Chiu YL, Au JS, et al. Dose-response relationship between cooking fumes exposures and lung cancer among Chinese nonsmoking women. Cancer Res 2006;66:4961-7.

18. Ko YC, Lee CH, Chen MJ, et al. Risk factors for primary lung cancer among non-smoking women in Taiwan. Int J Epidemiol 1997;26:24-31.

19. Ko YC, Cheng LS, Lee CH, et al. Chinese food cooking and lung cancer in women nonsmokers. Am J Epidemiol 2000;151:140-7.

20. Wang TJ, Zhou BS, Shi JP. Lung cancer in nonsmoking Chinese women: a case-control study. Lung Cancer 1996;14 Suppl 1:S93-8.

21. Xue Y, Jiang Y, Jin S, et al. Association between cooking oil fume exposure and lung cancer among Chinese nonsmoking women: a meta-analysis. Onco Targets Ther 2016;9:2987-92.

22. Wu PF, Lee CH, Wang MJ, et al. Cancer aggregation and complex segregation analysis of families with female nonsmoking lung cancer probands in Taiwan. Eur J Cancer 2004;40:260-6.

23. Jin $\mathrm{Y}, \mathrm{Xu} \mathrm{Y}, \mathrm{Xu} \mathrm{M}$, et al. Increased risk of cancer among relatives of patients with lung cancer in China. BMC Cancer 2005;5:146.

24. Jin YT, Xu YC, Yang RD, et al. Familial aggregation of lung cancer in a high incidence area in China. Br J Cancer 2005;92:1321-5.

25. Li P, Deng SS, Wang JB, et al. Occupational and environmental cancer incidence and mortality in China. Occup Med (Lond) 2012;62:281-7.

26. Taioli E, Wynder EL. Re: Endocrine factors and 
adenocarcinoma of the lung in women. J Natl Cancer Inst 1994;86:869-70.

27. Brenner AV, Wang Z, Kleinerman RA, et al. Previous pulmonary diseases and risk of lung cancer in Gansu Province, China. Int J Epidemiol 2001;30:118-24.

28. Wang SY, Hu YL, Wu YL, et al. A comparative study of the risk factors for lung cancer in Guangdong, China. Lung Cancer 1996;14 Suppl 1:S99-105.

29. Mizushima Y, Kobayashi M. Clinical characteristics of synchronous multiple lung cancer associated with idiopathic pulmonary fibrosis. A review of Japanese cases. Chest 1995;108:1272-7.

30. Engels EA, Shen M, Chapman RS, et al. Tuberculosis and subsequent risk of lung cancer in Xuanwei, China. Int J Cancer 2009; 124:1183-7.

31. Ren S, Kuang P, Zheng L, et al. Analysis of driver mutations in female non-smoker Asian patients with pulmonary adenocarcinoma. Cell Biochem Biophys 2012;64:155-60.

32. Li C, Fang R, Sun Y, et al. Spectrum of oncogenic driver mutations in lung adenocarcinomas from East Asian never smokers. PLoS One 2011;6:e28204.

33. Zhang Y, Sun Y, Pan Y, et al. Frequency of driver mutations in lung adenocarcinoma from female neversmokers varies with histologic subtypes and age at diagnosis. Clin Cancer Res 2012;18:1947-53.

34. Kim HR, Shim HS, Chung JH, et al. Distinct clinical features and outcomes in never-smokers with nonsmall cell lung cancer who harbor EGFR or KRAS mutations or ALK rearrangement. Cancer 2012;118:729-39.

35. Ha SY, Choi SJ, Cho JH, et al. Lung cancer in neversmoker Asian females is driven by oncogenic mutations, most often involving EGFR. Oncotarget 2015;6:5465-74.

36. Serizawa M, Koh Y, Kenmotsu H, et al. Assessment of mutational profile of Japanese lung adenocarcinoma patients by multitarget assays: a prospective, singleinstitute study. Cancer 2014;120:1471-81.

37. Li S, Choi YL, Gong Z, et al. Comprehensive Characterization of Oncogenic Drivers in Asian Lung Adenocarcinoma. J Thorac Oncol 2016;11:2129-40.

38. Zheng D, Wang R, Ye T, et al. MET exon 14 skipping defines a unique molecular class of non-small cell lung cancer. Oncotarget 2016;7:41691-702.

39. Gou LY, Niu FY, Wu YL, et al. Differences in driver genes between smoking-related and non-smoking-related lung cancer in the Chinese population. Cancer 2015;121 Suppl 17:3069-79.

40. An SJ, Chen ZH, Su J, et al. Identification of enriched driver gene alterations in subgroups of non-small cell lung cancer patients based on histology and smoking status. PLoS One 2012;7:e40109.

41. Li H, Pan Y, Li Y, et al. Frequency of well-identified oncogenic driver mutations in lung adenocarcinoma of smokers varies with histological subtypes and graduated smoking dose. Lung Cancer 2013;79:8-13.

42. Lynch TJ, Bell DW, Sordella R, et al. Activating mutations in the epidermal growth factor receptor underlying responsiveness of non-small-cell lung cancer to gefitinib. N Engl J Med 2004;350:2129-39.

43. Pao W, Miller V, Zakowski M, et al. EGF receptor gene mutations are common in lung cancers from "never smokers" and are associated with sensitivity of tumors to gefitinib and erlotinib. Proc Natl Acad Sci U S A 2004;101:13306-11.

44. Paez JG, Janne PA, Lee JC, et al. EGFR mutations in lung cancer: correlation with clinical response to gefitinib therapy. Science 2004;304:1497-500.

45. Wu YL, Zhou C, Hu CP, et al. Afatinib versus cisplatin plus gemcitabine for first-line treatment of Asian patients with advanced non-small-cell lung cancer harbouring EGFR mutations (LUX-Lung 6): an open-label, randomised phase 3 trial. Lancet Oncol 2014;15:213-22.

46. Mok TS, Wu YL, Thongprasert S, et al. Gefitinib or carboplatin-paclitaxel in pulmonary adenocarcinoma. N Engl J Med 2009;361:947-57.

47. Han JY, Park K, Kim SW, et al. First-SIGNAL: first-line single-agent iressa versus gemcitabine and cisplatin trial in never-smokers with adenocarcinoma of the lung. J Clin Oncol 2012;30:1122-8.

48. Wu YL, Zhou C, Liam CK, et al. First-line erlotinib versus gemcitabine/cisplatin in patients with advanced EGFR mutation-positive non-small-cell lung cancer: analyses from the phase III, randomized, open-label, ENSURE study. Ann Oncol 2015;26:1883-9.

49. Zhou C, Wu YL, Chen G, et al. Erlotinib versus chemotherapy as first-line treatment for patients with advanced EGFR mutation-positive non-small-cell lung cancer (OPTIMAL, CTONG-0802): a multicentre, open-label, randomised, phase 3 study. Lancet Oncol 2011;12:735-42.

50. Shi YK, Wang L, Han BH, et al. First-line icotinib versus cisplatin/pemetrexed plus pemetrexed maintenance therapy for patients with advanced EGFR mutation-positive lung adenocarcinoma (CONVINCE): a phase 3, open-label, randomized study. Ann Oncol 2017;28:2443-50.

51. Mitsudomi T, Morita S, Yatabe Y, et al. Gefitinib versus 
cisplatin plus docetaxel in patients with non-small-cell lung cancer harbouring mutations of the epidermal growth factor receptor (WJTOG3405): an open label, randomised phase 3 trial. Lancet Oncol 2010;11:121-8.

52. Maemondo M, Inoue A, Kobayashi K, et al. Gefitinib or chemotherapy for non-small-cell lung cancer with mutated EGFR. N Engl J Med 2010;362:2380-8.

53. Lee CK, Wu YL, Ding PN, et al. Impact of Specific Epidermal Growth Factor Receptor (EGFR) Mutations and Clinical Characteristics on Outcomes After Treatment With EGFR Tyrosine Kinase Inhibitors Versus Chemotherapy in EGFR-Mutant Lung Cancer: A MetaAnalysis. J Clin Oncol 2015;33:1958-65.

54. Park K, Yu CJ, Kim SW, et al. First-Line Erlotinib Therapy Until and Beyond Response Evaluation Criteria in Solid Tumors Progression in Asian Patients With Epidermal Growth Factor Receptor Mutation-Positive Non-Small-Cell Lung Cancer: The ASPIRATION Study. JAMA Oncol 2016;2:305-12.

55. Schuler M, Yang JC, Park K, et al. Afatinib beyond progression in patients with non-small-cell lung cancer following chemotherapy, erlotinib/gefitinib and afatinib: phase III randomized LUX-Lung 5 trial. Ann Oncol 2016;27:417-23.

56. Soria JC, Wu YL, Nakagawa K, et al. Gefitinib plus chemotherapy versus placebo plus chemotherapy in EGFR-mutation-positive non-small-cell lung cancer after progression on first-line gefitinib (IMPRESS): a phase 3 randomised trial. Lancet Oncol 2015;16:990-8.

57. Mok TSK, Kim SW, Wu YL, et al. Gefitinib Plus Chemotherapy Versus Chemotherapy in Epidermal Growth Factor Receptor Mutation-Positive Non-SmallCell Lung Cancer Resistant to First-Line Gefitinib (IMPRESS): Overall Survival and Biomarker Analyses. J Clin Oncol 2017;35:4027-34.

58. Ding T, Zhou F, Chen X, et al. Continuation of gefitinib plus chemotherapy prolongs progression-free survival in advanced non-small cell lung cancer patients who get acquired resistance to gefitinib without T790M mutations. J Thorac Dis 2017;9:2923-34.

59. Kuiper JL, Heideman DA, Thunnissen E, et al. Incidence of T790M mutation in (sequential) rebiopsies in EGFRmutated NSCLC-patients. Lung Cancer 2014;85:19-24.

60. Li W, Ren S, Li J, et al. T790M mutation is associated with better efficacy of treatment beyond progression with EGFR-TKI in advanced NSCLC patients. Lung Cancer 2014;84:295-300.

61. Nosaki K, Satouchi M, Kurata T, et al. Re-biopsy status among non-small cell lung cancer patients in Japan: A retrospective study. Lung Cancer 2016;101:1-8.

62. Wu SG, Liu YN, Tsai MF, et al. The mechanism of acquired resistance to irreversible EGFR tyrosine kinase inhibitor-afatinib in lung adenocarcinoma patients. Oncotarget 2016;7:12404-13.

63. Janne PA, Yang JC, Kim DW, et al. AZD9291 in EGFR inhibitor-resistant non-small-cell lung cancer. N Engl J Med 2015;372:1689-99.

64. Yang JC, Ahn MJ, Kim DW, et al. Osimertinib in Pretreated T790M-Positive Advanced Non-SmallCell Lung Cancer: AURA Study Phase II Extension Component. J Clin Oncol 2017;35:1288-96.

65. Goss G, Tsai CM, Shepherd FA, et al. Osimertinib for pretreated EGFR Thr790Met-positive advanced nonsmall-cell lung cancer (AURA2): a multicentre, open-label, single-arm, phase 2 study. Lancet Oncol 2016;17:1643-52.

66. Mok TS, Wu YL, Ahn MJ, et al. Osimertinib or PlatinumPemetrexed in EGFR T790M-Positive Lung Cancer. N Engl J Med 2017;376:629-40.

67. Zhou C, Wang M, Cheng Y, et al. Osimertinib in AsiaPacific patients (pts) with EGFR T790M-positive advanced NSCLC: Updated Phase II study results including progression-free survival (PFS). Ann Oncol 2017;1354P. abtract.

68. Soda M, Choi YL, Enomoto M, et al. Identification of the transforming EML4-ALK fusion gene in non-small-cell lung cancer. Nature 2007;448:561-6.

69. Pan Y, Zhang Y, Li Y, et al. ALK, ROS1 and RET fusions in 1139 lung adenocarcinomas: a comprehensive study of common and fusion pattern-specific clinicopathologic, histologic and cytologic features. Lung Cancer 2014;84:121-6.

70. Solomon BJ, Mok T, Kim DW, et al. First-line crizotinib versus chemotherapy in ALK-positive lung cancer. N Engl J Med 2014;371:2167-77.

71. Nishio M, Kim DW, Wu YL, et al. Crizotinib Versus Chemotherapy in Asian Patients with Advanced ALKpositive Non-small Cell Lung Cancer. Cancer Res Treat 2018;50:691-700.

72. Lu S, Mok T, Lu Y, et al. Phase 3 study of first-line crizotinib vs pemetrexedcisplatin/carboplatin (PCC) in East Asian patients with ALK+ advanced non-squamous non-small cell lung cancer (NSCLC). J Clin Oncol 2016;34:9058.

73. Gadgeel SM, Gandhi L, Riely GJ, et al. Safety and activity of alectinib against systemic disease and brain metastases in patients with crizotinib-resistant ALK-rearranged 
non-small-cell lung cancer (AF-002JG): results from the dose-finding portion of a phase 1/2 study. Lancet Oncol 2014;15:1119-28.

74. Kodama T, Tsukaguchi T, Yoshida M, et al. Selective ALK inhibitor alectinib with potent antitumor activity in models of crizotinib resistance. Cancer Lett 2014;351:215-21.

75. Seto T, Kiura K, Nishio M, et al. CH5424802 (RO5424802) for patients with ALK-rearranged advanced non-small-cell lung cancer (AF-001JP study): a single-arm, open-label, phase 1-2 study. Lancet Oncol 2013;14:590-8.

76. Hida T, Nokihara H, Kondo M, et al. Alectinib versus crizotinib in patients with ALK-positive non-small-cell lung cancer (J-ALEX): an open-label, randomised phase 3 trial. Lancet 2017;390:29-39.

77. Peters S, Camidge DR, Shaw AT, et al. Alectinib versus Crizotinib in Untreated ALK-Positive Non-Small-Cell Lung Cancer. N Engl J Med 2017;377:829-38.

78. Rikova K, Guo A, Zeng Q, et al. Global survey of phosphotyrosine signaling identifies oncogenic kinases in lung cancer. Cell 2007;131:1190-203.

79. Bergethon K, Shaw AT, Ou SH, et al. ROS1 rearrangements define a unique molecular class of lung cancers. J Clin Oncol 2012;30:863-70.

80. Davies KD, Le AT, Theodoro MF, et al. Identifying and targeting ROS1 gene fusions in non-small cell lung cancer. Clin Cancer Res 2012;18:4570-9.

81. Yoshida A, Kohno T, Tsuta K, et al. ROS1-rearranged lung cancer: a clinicopathologic and molecular study of 15 surgical cases. Am J Surg Pathol 2013;37:554-62.

82. Cai W, Li X, Su C, et al. ROS1 fusions in Chinese patients with non-small-cell lung cancer. Ann Oncol 2013;24:1822-7.

83. Suehara Y, Arcila M, Wang L, et al. Identification of KIF5B-RET and GOPC-ROS1 fusions in lung adenocarcinomas through a comprehensive mRNAbased screen for tyrosine kinase fusions. Clin Cancer Res 2012;18:6599-608.

84. Rimkunas VM, Crosby KE, Li D, et al. Analysis of receptor tyrosine kinase ROS1-positive tumors in nonsmall cell lung cancer: identification of a FIG-ROS1 fusion. Clin Cancer Res 2012;18:4449-57.

85. Shaw AT, Ou SH, Bang YJ, et al. Crizotinib in ROS1rearranged non-small-cell lung cancer. N Engl J Med 2014;371:1963-71.

86. Lim SM, Kim HR, Lee JS, et al. Open-Label, Multicenter, Phase II Study of Ceritinib in Patients With Non-SmallCell Lung Cancer Harboring ROS1 Rearrangement. J Clin Oncol 2017;35:2613-8.
87. Shaw AT, Felip E, Bauer TM, et al. Lorlatinib in nonsmall-cell lung cancer with ALK or ROS1 rearrangement: an international, multicentre, open-label, single-arm firstin-man phase 1 trial. Lancet Oncol 2017;18:1590-9.

88. Drilon A, Siena S, Ou SI, et al. Safety and Antitumor Activity of the Multitargeted Pan-TRK, ROS1, and ALK Inhibitor Entrectinib: Combined Results from Two Phase I Trials (ALKA-372-001 and STARTRK-1). Cancer Discov 2017;7:400-9.

89. Chong CR, Bahcall M, Capelletti M, et al. Identification of Existing Drugs That Effectively Target NTRK1 and ROS1 Rearrangements in Lung Cancer. Clin Cancer Res 2017;23:204-13.

90. Goto K, Yang JC, Kim DW, et al. Phase II study of crizotinib in East Asian patients (pts) with ROS1-positive advanced non-small cell lung cancer (NSCLC). J Clin Oncol 2016;34:9022.

91. Wang R, Hu H, Pan Y, et al. RET fusions define a unique molecular and clinicopathologic subtype of non-small-cell lung cancer. J Clin Oncol 2012;30:4352-9.

92. Cai W, Su C, Li X, et al. KIF5B-RET fusions in Chinese patients with non-small cell lung cancer. Cancer 2013;119:1486-94.

93. Drilon A, Rekhtman N, Arcila M, et al. Cabozantinib in patients with advanced RET-rearranged non-small-cell lung cancer: an open-label, single-centre, phase 2, singlearm trial. Lancet Oncol 2016;17:1653-60.

94. Yoh K, Seto T, Satouchi M, et al. Vandetanib in patients with previously treated RET-rearranged advanced nonsmall-cell lung cancer (LURET): an open-label, multicentre phase 2 trial. Lancet Respir Med 2017;5:42-50.

95. Drilon A, Wang L, Hasanovic A, et al. Response to Cabozantinib in patients with RET fusion-positive lung adenocarcinomas. Cancer Discov 2013;3:630-5.

96. Gautschi O, Milia J, Filleron T, et al. Targeting RET in Patients With RET-Rearranged Lung Cancers: Results From the Global, Multicenter RET Registry. J Clin Oncol 2017;35:1403-10.

97. Frampton GM, Ali SM, Rosenzweig M, et al. Activation of MET via diverse exon 14 splicing alterations occurs in multiple tumor types and confers clinical sensitivity to MET inhibitors. Cancer Discov 2015;5:850-9.

98. Awad MM, Oxnard GR, Jackman DM, et al. MET Exon 14 Mutations in Non-Small-Cell Lung Cancer Are Associated With Advanced Age and Stage-Dependent MET Genomic Amplification and c-Met Overexpression. J Clin Oncol 2016;34:721-30.

99. Lee GD, Lee SE, Oh DY, et al. MET Exon 14 Skipping 
Mutations in Lung Adenocarcinoma: Clinicopathologic Implications and Prognostic Values. J Thorac Oncol 2017;12:1233-46.

100.Liu SY, Gou LY, Li AN, et al. The Unique Characteristics of MET Exon 14 Mutation in Chinese Patients with NSCLC. J Thorac Oncol 2016;11:1503-10.

101.Jorge SE, Schulman S, Freed JA, et al. Responses to the multitargeted MET/ALK/ROS1 inhibitor crizotinib and co-occurring mutations in lung adenocarcinomas with MET amplification or MET exon 14 skipping mutation. Lung Cancer 2015;90:369-74.

102. Shigematsu H, Takahashi T, Nomura M, et al. Somatic mutations of the HER2 kinase domain in lung adenocarcinomas. Cancer Res 2005;65:1642-6.

103.Song Z, Yu X, Shi Z, et al. HER2 mutations in Chinese patients with non-small cell lung cancer. Oncotarget 2016;7:78152-8.

104. Shan L, Qiu T, Ling Y, et al. Prevalence and Clinicopathological Characteristics of HER2 and BRAF Mutation in Chinese Patients with Lung Adenocarcinoma. PLoS One 2015;10:e0130447.

105.Li X, Zhao C, Su C, et al. Epidemiological study of HER2 mutations among EGFR wild-type lung adenocarcinoma patients in China. BMC Cancer 2016;16:828.

106. Mazieres J, Peters S, Lepage B, et al. Lung cancer that harbors an HER2 mutation: epidemiologic characteristics and therapeutic perspectives. J Clin Oncol 2013;31:1997-2003.

107.Eng J, Hsu M, Chaft JE, et al. Outcomes of chemotherapies and HER2 directed therapies in advanced HER2-mutant lung cancers. Lung Cancer 2016;99:53-6.

108. De Greve J, Teugels E, Geers C, et al. Clinical activity of afatinib (BIBW 2992) in patients with lung adenocarcinoma with mutations in the kinase domain of HER2/neu. Lung Cancer 2012;76:123-7.

109. Gandhi L, Bahleda R, Tolaney SM, et al. Phase I study of neratinib in combination with temsirolimus in patients with human epidermal growth factor receptor 2-dependent and other solid tumors. J Clin Oncol 2014;32:68-75.

110.Kris MG, Camidge DR, Giaccone G, et al. Targeting HER2 aberrations as actionable drivers in lung cancers: phase II trial of the pan-HER tyrosine kinase inhibitor dacomitinib in patients with HER2-mutant or amplified tumors. Ann Oncol 2015;26:1421-7.

111.Li X, Yang C, Wan H, et al. Discovery and development of pyrotinib: A novel irreversible EGFR/HER2 dual tyrosine kinase inhibitor with favorable safety profiles for the treatment of breast cancer. Eur J Pharm Sci
2017;110:51-61.

112.Ma F, Li Q, Chen S, et al. Phase I Study and Biomarker Analysis of Pyrotinib, a Novel Irreversible Pan-ErbB Receptor Tyrosine Kinase Inhibitor, in Patients With Human Epidermal Growth Factor Receptor 2-Positive Metastatic Breast Cancer. J Clin Oncol 2017;35:3105-12.

113. Ren S, Zhou C, Gao G, et al. Preliminary results of a phase II study about the efficacy and safety of pyrotinib in patients with HER2 mutant advanced NSCLC. Journal of Thoracic Oncology 2016;12:MA04.3.

114. Huang Y, Wang R, Pan Y, et al. Clinical and genetic features of lung squamous cell cancer in never-smokers. Oncotarget 2016;7:35979-88.

115.Lee HY, Lee SH, Won JK, et al. Analysis of Fifty Hotspot Mutations of Lung Squamous Cell Carcinoma in Neversmokers. J Korean Med Sci 2017;32:415-20.

116. Hata A, Katakami N, Yoshioka H, et al. How sensitive are epidermal growth factor receptor-tyrosine kinase inhibitors for squamous cell carcinoma of the lung harboring EGFR gene-sensitive mutations? J Thorac Oncol 2013;8:89-95.

117.Xu J, Zhang Y, Jin B, et al. Efficacy of EGFR tyrosine kinase inhibitors for non-adenocarcinoma lung cancer patients harboring EGFR-sensitizing mutations in China. J Cancer Res Clin Oncol 2016;142:1325-30.

118. Wang Q, He Y, Yang X, et al. Extraordinary response to crizotinib in a woman with squamous cell lung cancer after two courses of failed chemotherapy. BMC Pulm Med 2014;14:83.

119.Zhang Q, Wang J, Zhang S. ALK-rearranged squamous cell lung cancer: a case report. Int J Clin Exp Pathol 2015;8:2195-8.

120. Wang W, Song Z, Zhang Y. Response to crizotinib in a squamous cell lung carcinoma patient harbouring echinoderm microtubule-associated protein-like 4-anaplastic lymphoma translocation: A case report. Thorac Cancer 2016;7:355-7.

121. Mamesaya N, Nakashima K, Naito T, et al. ALKrearranged lung squamous cell carcinoma responding to alectinib: a case report and review of the literature. BMC Cancer 2017;17:471.

122.Li Q, Wu J, Yan LX, et al. ALK and ROS1 DoubleRearranged Lung Squamous Cell Carcinoma Responding to Crizotinib Treatment: A Case Report. J Thorac Oncol 2017;12:e193-7.

123. Tamiya A, Shimizu S, Atagi S. A Case of Squamous Cell Carcinoma Harboring an EML4-ALK Rearrangement that Was Unsuccessfully Treated with the ALK Inhibitor Alectinib. J Thorac Oncol 2015;10:e74. 
124. Varghese AM, Zakowski MF, Yu HA, et al. Small-cell lung cancers in patients who never smoked cigarettes. J Thorac Oncol 2014;9:892-6.

125. Ou SH, Ziogas A, Zell JA. Prognostic factors for survival in extensive stage small cell lung cancer (ED-SCLC): the importance of smoking history, socioeconomic and marital statuses, and ethnicity. J Thorac Oncol 2009;4:37-43.

126. Le X, Desai NV, Majid A, et al. De novo pulmonary small cell carcinomas and large cell neuroendocrine carcinomas harboring EGFR mutations: Lack of response to EGFR inhibitors. Lung Cancer 2015;88:70-3.

127. Morgensztern D, Herbst RS. Nivolumab and Pembrolizumab for Non-Small Cell Lung Cancer. Clin Cancer Res 2016;22:3713-7.

128. Brahmer J, Reckamp KL, Baas P, et al. Nivolumab versus Docetaxel in Advanced Squamous-Cell Non-Small-Cell Lung Cancer. N Engl J Med 2015;373:123-35.

129. Borghaei H, Paz-Ares L, Horn L, et al. Nivolumab versus Docetaxel in Advanced Nonsquamous Non-Small-Cell Lung Cancer. N Engl J Med 2015;373:1627-39.

130. Herbst RS, Baas P, Kim DW, et al. Pembrolizumab versus docetaxel for previously treated, PD-L1-positive, advanced non-small-cell lung cancer (KEYNOTE-010): a randomised controlled trial. Lancet 2016;387:1540-50.

131. Fehrenbacher L, Spira A, Ballinger M, et al. Atezolizumab versus docetaxel for patients with previously treated non-small-cell lung cancer (POPLAR): a multicentre, open-label, phase 2 randomised controlled trial. Lancet 2016;387:1837-46.

132. Rittmeyer A, Barlesi F, Waterkamp D, et al. Atezolizumab versus docetaxel in patients with previously treated non-small-cell lung cancer (OAK): a phase 3, openlabel, multicentre randomised controlled trial. Lancet 2017;389:255-65

133. Reck M, Rodriguez-Abreu D, Robinson AG, et al. Pembrolizumab versus Chemotherapy for PD-L1Positive Non-Small-Cell Lung Cancer. N Engl J Med 2016;375:1823-33.

134. Rizvi NA, Hellmann MD, Snyder A, et al. Cancer immunology. Mutational landscape determines sensitivity

Cite this article as: Zhou F, Zhou C. Lung cancer in never smokers-the East Asian experience. Transl Lung Cancer Res 2018;7(4):450-463. doi: 10.21037/tlcr.2018.05.14 to PD-1 blockade in non-small cell lung cancer. Science 2015;348:124-8.

135. Carbone DP, Reck M, Paz-Ares L, et al. First-Line Nivolumab in Stage IV or Recurrent Non-Small-Cell Lung Cancer. N Engl J Med 2017;376:2415-26.

136. Kinoshita T, Kudo-Saito C, Muramatsu R, et al. Determination of poor prognostic immune features of tumour microenvironment in non-smoking patients with lung adenocarcinoma. Eur J Cancer 2017;86:15-27.

137.Lee CK, Man J, Lord S, et al. Clinical and Molecular Characteristics Associated With Survival Among Patients Treated With Checkpoint Inhibitors for Advanced NonSmall Cell Lung Carcinoma: A Systematic Review and Meta-analysis. JAMA Oncol 2018;4:210-216.

138. Lee CK, Man J, Lord S, et al. Checkpoint Inhibitors in Metastatic EGFR-Mutated Non-Small Cell Lung Cancer-A Meta-Analysis. J Thorac Oncol 2017;12:403-7.

139. Gainor JF, Shaw AT, Sequist LV, et al. EGFR Mutations and ALK Rearrangements Are Associated with Low Response Rates to PD-1 Pathway Blockade in Non-Small Cell Lung Cancer: A Retrospective Analysis. Clin Cancer Res 2016;22:4585-93.

140.Dong ZY, Zhang JT, Liu SY, et al. EGFR mutation correlates with uninflamed phenotype and weak immunogenicity, causing impaired response to PD-1 blockade in non-small cell lung cancer. Oncoimmunology 2017;6:e1356145.

141. Streicher K, Higgs BW, Wu S, et al. Increased CD73 and reduced IFNG signature expression in relation to response rates to anti-PD-1(L1) therapies in EGFR-mutant NSCLC. J Clin Oncol 2017;35:11505.

142.Sabari JK, Montecalvo J, Chen R, et al. PD-L1 expression and response to immunotherapy in patients with MET exon 14-altered non-small cell lung cancers (NSCLC). J Clin Oncol 2017;35:8512.

143.Zhang Y, Wang Q, Han ZG, et al. Differences in epidermal growth factor receptor gene mutations and relationship with clinicopathological features in NSCLC between Uygur and Han ethnic groups. Asian Pac J Cancer Prev 2013;14:2879-83. 